\title{
BOND BEHAVIOR OF NEAR-SURFACE MOUNTED CFRP LAMINATE STRIPS UNDER MONOTONIC AND CYCLIC LOADING
}

\author{
José M. Sena Cruz ${ }^{1}$, Joaquim A. O. Barros ${ }^{2}$, Ravindra Gettu ${ }^{3}$ and Álvaro F. M. Azevedo ${ }^{4}$
}

\begin{abstract}
Near-surface mounted (NSM) carbon fiber reinforced polymer (CFRP) laminate strips are used to increase the load-carrying capacity of concrete structures by inserting them into slits made in the concrete cover of the elements to be strengthened and gluing them to the concrete with an epoxy adhesive. In several cases the NSM technique has substantial advantages when compared with externally bonded laminates. In order to assess the bond behavior between the CFRP and concrete under monotonic and cyclic loading, an experimental program, based on a series of pullout-bending tests, was carried out. The influence of the bond length and loading history on the bond behavior was investigated. In this work the details of the tests are described, and the obtained results are discussed. Using the experimental data and an analytical-numerical strategy, a local bond stress-slip relationship was determined. A finite element analysis was performed to evaluate the influence of the adhesive on the global response observed in the pullout-bending tests.
\end{abstract}

CE Database subject headings: Bonding; Experimentation; Cyclic loads; Fiber reinforced materials; Concrete; Numerical analysis.

\section{Introduction}

The near-surface mounted (NSM) technique using laminate strips of carbon fiber reinforced polymer (CFRP) has been proposed as a strengthening strategy to increase the load carrying capacity of concrete members. The term 'near-surface' is used to distinguish this technique from the case where externally bonded FRP reinforcement (EBR) is utilized. The proposed NSM technique consists of inserting CFRP laminate strips into saw cuts or slits made in the concrete cover of the elements to be strengthened. This concept is not completely new, since it was first used in Europe for the strengthening of reinforced concrete structures in the 1940s. This pioneering

\footnotetext{
${ }^{1}$ Assistant Professor, Dept. of Civil Engineering, Univ. of Minho, Campus de Azurém, 4810-058 Guimarães, Portugal. E-mail: jsena@civil.uminho.pt; Corresponding author

${ }^{2}$ Associate Professor, Dept. of Civil Engineering, Univ. of Minho, Campus de Azurém, 4810-058 Guimarães, Portugal. E-mail: barros@civil.uminho.pt

${ }^{3}$ Professor, Dept. of Civil Engineering, Indian Institute of Technology Madras, Chennai 600036, India. E-mail: gettu@iitm.ac.in

${ }^{4}$ Assistant Professor, Dept. of Civil Engineering, Univ. of Porto, Rua Dr. Roberto Frias, s/n, 4200-465 Porto, Portugal. E-mail: alvaro@fe.up.pt
} 
technique consisted of placing reinforcing bars in grooves located in the concrete cover. The grooves were then filled with cement mortar (Asplund 1949). In the present work, FRP laminates take the place of the rebars and an epoxy adhesive replaces the cement mortar. This "reinvented" technique has been used in some applications and several benefits have been pointed out, namely, high levels of strengthening efficacy and, when compared with EBR, a significant decrease of the probability of damage resulting from fire, acts of vandalism, mechanical actions and aging effects (Ferreira 2001, Barros and Fortes 2002, Tan et al. 2002, Barros and Dias 2003, Hassan and Rizkalla 2003). Besides, the complete installation time associated with the NSM technique is less than in the case of the EBR technique (Barros and Dias 2003).

Since structural strengthening with the NSM CFRP laminate strips is an emerging technique, the bond behavior is an important issue that requires more research. In the current context, bond is the phenomenon, which allows the transfer of stresses between the concrete and the reinforcement during the loading process of reinforced concrete elements. The bond performance influences the ultimate load-carrying capacity of a reinforced element, as well as some serviceability aspects, such as crack width and crack spacing. In a previous work, the influence of bond length, $L_{b}$, and concrete strength, $f_{c m}$, on the bond performance has been assessed through pullout-bending tests under monotonic loading on specimens with $L_{b}=40,60$ or $80 \mathrm{~mm}$ and $f_{c m}=35,45$ or $70 \mathrm{MPa}$ (Sena-Cruz and Barros 2004a). It was shown that the test setup used in the experimental program was adequate for the evaluation of the bond performance between CFRP laminate strips and concrete. It was also concluded, from a parametric study, that the peak pullout force, the loaded-end slip and the bond strength were significantly influenced by the bond length but were independent of the concrete strength.

Bond between reinforcement and concrete is intrinsically a three-dimensional problem. Due to its complexity and for the purpose of developing analytical formulations, it is split into two unidimensional or bidimensional problems (FIB 2000). Bond behavior along the reinforcement can be treated as a uniaxial problem, and can be modeled by solving the corresponding differential equation, for which the local bond stress-slip relationship must be known. Several researchers have modeled the longitudinal bond behavior of rebars, assuming that the slip and the bond stress are constant along the bond length. Using this approach, which is acceptable for rebars, empirical equations for the local bond stress-slip relationship have been proposed (e.g., Eligehausen et al. 1983). In early works dealing with the analytical modeling of the bond of FRP bars to concrete, the methodology formerly adopted for the rebars was followed. Several researchers have considered a constant slip and bond stress throughout the bond length and, based on this assumption, have proposed different local bond stress-slip relationships for modeling the behavior (Cosenza et al. 1997, De Lorenzis et al. 2002). 
However, for the case of FRP reinforcement this approach is inaccurate, since the distribution of the slip and bond stress along the bond length is significantly nonlinear (Focacci et al. 2000).

In order to assess the influence of the bond length and load history on the bond performance of the NSM strengthening technique, an experimental program was carried out. These tests are described, and the results obtained are presented and analyzed in the following sections. In accordance with these results, an analytical local bond stress-slip relationship is proposed. The influence of the adhesive on the global response observed in the pullout-bending tests was evaluated through finite element analysis.

\section{Experimental Program}

\section{Specimen and Test Configuration}

Fig. 1 shows the pullout-bending test setup adopted in this study. Concrete blocks A and B are connected by a steel hinge located at mid-span close to the top, and by the CFRP laminate fixed at the bottom. The bond test region was located in block A, with the bond length, $L_{b}$, being one of the variables. In order to ensure negligible slip of the laminate fixed to block B and to force bond failure in block A, the laminate was bonded over a considerable length in block B. The slit made for the insertion of the CFRP was $15 \mathrm{~mm}$ deep and $4.8 \mathrm{~mm}$ wide; these dimensions are typical for cuts that can be easily made on site with a rotary saw.

The displacement transducer LVDT2 was used to control the test and also to measure the slip at the loaded-end, $s_{l}$, while the transducer LVDT1 was used to measure the slip at the free-end, $s_{f}$. Note that the loaded-end slip values include the elastic axial deformation of the laminate. A constant $5 \mu \mathrm{m} / \mathrm{s}$ loaded-end slip rate was applied in the tests. This slip rate leads to quasi-static tests where dynamic as well as creep effects are negligible. The strain gage glued to the CFRP at the mid-span of the specimen was used to estimate the pullout force of the laminate. A load cell mounted on the actuator was used to measure the total applied force $F$. The tests were performed in a servohydraulic INSTRON 8505 system of $1 \mathrm{MN}$ capacity with a closed-loop digital controller. Further details on the characteristics of the test setup can be found in Sena-Cruz (2004).

\section{Test Procedure}

Suitable bond lengths were adopted in order to avoid the rupture of the CFRP laminate during the test. For this purpose, some preliminary tests were carried out with different bond lengths. Based on these results, the range of $60 \mathrm{~mm}$ to $120 \mathrm{~mm}$ was chosen for the bond length. The lower limit of $60 \mathrm{~mm}$ was considered to minimize the 
end effects, and the upper limit of $120 \mathrm{~mm}$ was adopted due to limitations associated with the geometry of the specimen.

The influence of the loading history on the bond performance associated with the NSM strengthening technique was treated in the present study by considering the following three types of load configurations: monotonic loading (M), one cycle of unloading/reloading at different slip levels (C1) and ten cycles of unloading/reloading for a fixed load level (C10).

The experimental program consists of seven series of tests (see Table 1), each consisting of tests on three specimens. The generic denomination of each series is LbX_Y, where $\mathrm{X}$ is the CFRP bond length in millimeters $(60,90$ or $120 \mathrm{~mm})$, and $\mathrm{Y}$ is the type of load configuration (M, C1 or C10).

Three distinct C10 load configurations were adopted, whose denominations are: Lb60_C10 series, Lb90_C10 series and Lb120_C10 series. In these series, the load level at the onset of the unloading/reloading cycles was $90 \%, 60 \%$ and $75 \%$ of the peak pullout force, respectively. After the unloading/reloading cycles, the loading was continued monotonically until a $5 \mathrm{~mm}$ loaded-end slip measured with LVDT2 (see Fig. 2). The objective of the application of unloading/reloading cycles before reaching the maximum pullout force was to assess the influence of the cyclic loading on the bond strength. Cycles were performed at different bond stress levels $(60 \%, 75 \%$ or $90 \%)$ to evaluate the influence of this parameter on the bond stress degradation and on the consequent variation of the bond strength.

In the $\mathrm{C} 1$ load configuration (see Fig. 3) one unloading/reloading cycle was performed at a slip of $250 \mu \mathrm{m}, 500 \mu \mathrm{m}, 750 \mu \mathrm{m}, 1000 \mu \mathrm{m}, 1500 \mu \mathrm{m}, 2000 \mu \mathrm{m}, 3000 \mu \mathrm{m}$ and $4000 \mu \mathrm{m}$. This load configuration was selected in order to investigate the influence of the cyclic loading on the variation of the stiffness. Due to some limitations of the testing equipment, all unloading phases were performed under load control with a predetermined load rate that corresponds to an average slip rate of $5 \mu \mathrm{m} / \mathrm{s}$.

\section{Material Properties}

Concrete designed for a characteristic 28-day cylinder compressive strength of $30 \mathrm{MPa}$ was used in the study.

The grain size distributions of the sand and gravel used, and the composition of the concrete are given in Sena-Cruz (2004). In order to avoid shear failure of the concrete blocks, as observed in previous studies (Sena-Cruz et al. 2001), $60 \mathrm{~kg} / \mathrm{m}^{3}$ of hooked end steel fibers were incorporated in the concrete to increase its shear cracking resistance. Adding fibers to concrete does not affect the bond behavior, since concrete cracking is not expected to occur in the bonding zone (Ezeldin and Balaguru 1989). Cylinder specimens with a diameter of 
$150 \mathrm{~mm}$ and a height of $300 \mathrm{~mm}$ were used to obtain the compressive strength of the concrete. The compression tests were carried out in an IBERTEST machine under load control at a rate of $0.5 \mathrm{MPa} / \mathrm{s}$. An average compressive strength of 41.0 $\pm 0.9 \mathrm{MPa}$ was obtained at the age of the pullout-bending tests (Sena-Cruz 2004).

The CFRP strips used as inserts had a thickness of $1.4 \mathrm{~mm}$ and a width of $10.0 \mathrm{~mm}$. The CFRP used is composed of unidirectional carbon fibers in an epoxy matrix, and the strips have a smooth surface. From five uniaxial tensile tests carried out according to the ISO 527-5 (1997) recommendations, the following properties were obtained: Young's modulus of elasticity equal to $171 \pm 1 \mathrm{GPa}$, tensile strength equal to $2.83 \pm 0.16 \mathrm{GPa}$, and ultimate strain equal to $1.55 \pm 0.10 \%$.

The laminate was bonded to concrete with a low-viscosity epoxy (Mbrace Epoxikleber 220). In order to characterize the epoxy, three-point bending and compression tests were carried out, following the NP-EN 196-1 (1987) recommendations. The epoxy components were mixed in a mortar mixer, placed in the molds and jolted to ensure adequate filling. The specimens were cured in a curing chamber $\left(20^{\circ} \mathrm{C}\right.$ and $\left.50 \% \mathrm{RH}\right)$. Further details regarding the preparation of the epoxy specimens and the corresponding curing procedures can be found elsewhere (Sena-Cruz 2004). The bending tests were carried out in a universal test machine, under load control, at a rate of $50 \mathrm{~N} / \mathrm{s}$, and a tensile strength of $21.8 \pm 5.5 \mathrm{MPa}$ was obtained from three specimens. In the fracture surface of the specimens several voids were observed, which can be responsible for the large coefficient of variation (i.e., $25 \%$ ). After completing the bending tests, the half-beams were tested in compression. These tests were performed in a universal testing machine, under load control, at a rate of $2.4 \mathrm{kN} / \mathrm{s}$, and a compressive strength of $67.5 \pm 3.6 \mathrm{MPa}$ was obtained from six epoxy specimens.

\section{Specimen Preparation}

The blocks that comprise the pullout-bending specimens were cured in a fog room for 28 days after casting. A table-mounted saw was used in order to open the slits. Then, these slits were cleaned with compressed water to eliminate the remaining dust induced by the sawing process. Afterwards, the specimens were air-dried in the laboratory environment during at least one week before the CFRP laminates were bonded. Immediately before bonding the CFRP laminate, the slits were cleaned with a jet of compressed air. In order to avoid the flow of epoxy adhesive to beyond the bond length, a masking procedure was adopted (Sena-Cruz 2004).

The preparation of the CFRP strip involved the following steps: delimiting the bond length carefully; gluing a strain gage at mid-span; and, finally cleaning the CFRP with acetone (Sena-Cruz 2004). 
In the bond regions the slit was completely filled with epoxy adhesive. In the corresponding lateral surfaces the laminate was covered with a thin layer of epoxy adhesive. Afterwards, the laminate was inserted forcibly into the slit resulting in the flow of excess adhesive out of the slit. Finally, the overflowed epoxy adhesive was removed and the surface was leveled. The specimens were kept for several weeks in the laboratory environment before being tested.

\section{Results}

In all the tested specimens, slip was mainly localized along the CFRP-adhesive interface. This was to be expected since the rougher surface of the concrete leads to better bonding with the adhesive, resulting in much more slip at the laminate-adhesive interface during failure than along the concrete-adhesive interface. Additionally, fine cracks in a fishbone pattern were observed in the epoxy adhesive (see Fig. 4). No cracks were observed on the concrete surface justifying the assumption that the concrete tensile strength and the addition of fibers to the concrete play a negligible role in the behavior observed in the present tests.

\section{Monotonic results}

Fig. 5 shows typical relationships between the pullout force and the slip, at both the free-end and loaded-end $\left(F_{l}-s_{f}\right.$ and $\left.F_{l}-s_{l}\right)$, for the monotonic load configuration. Complete details related to monotonic loading can be found in Sena-Cruz (2004). In the present work, the loaded-end slip includes the axial deformation of the laminate. The calculation of the pullout force in the CFRP, $F_{l}$, was based on the strains recorded by the gages mounted on the CFRP laminate, considering a modulus of elasticity of $171 \mathrm{GPa}$ and a cross sectional area of $14.04 \mathrm{~mm}^{2}$. Fig. 5 shows the nonlinear relationship between the slip and the pullout force. For all the monotonic tests, peak loads occurred at loaded-end slips ranging from $0.27 \mathrm{~mm}$ to $1.24 \mathrm{~mm}$. After a sharp post-peak drop, the pullout force slowly decreases with an increase in the slip. The residual pullout forces, which are significant, indicate that frictional mechanisms in the laminate-adhesive-concrete interfaces are mobilized during the pullout failure.

In order to assess the bond performance under monotonic loading, the following parameters have been analyzed (see Table 1):

- $\quad S_{l \max }$ is the slip at the loaded-end at the peak pullout force $\left(F_{l \max }\right)$; 
- $\tau_{\max }$ is the average bond strength, obtained by dividing the peak pullout force by the contact area between the CFRP and the epoxy adhesive, $F_{l \max } /\left(2 w_{f} L_{b}\right)$, where $w_{f}$ is the width of the laminate;

- $\quad \sigma_{l \max } / f_{f u}$ is the ratio between the axial stress in the laminate at the peak pullout force and its tensile strength;

- $\tau_{r} / \tau_{\max }$ is the residual bond stress ratio, where $\tau_{r}$ is the average bond stress at the end of the test, which corresponds to a $5 \mathrm{~mm}$ loaded-end slip.

As expected, the parameters $s_{l \max }, F_{l \max }, \sigma_{l \max } / f_{f u}$ and $\tau_{r} / \tau_{\max }$ increase with the bond length, $L_{b}$. The average peak bond stress, $\tau_{\max }$, however, decreases with $L_{b}$.

\section{Cyclic loading results}

Fig. 6 presents, for the $\mathrm{C} 10$ series, the typical evolutions of the slip at the free-end and loaded-end, and of the pullout force. As this figure shows, the free-end slip is negligible during the unloading/reloading cycles indicating that the bond failure has not progressed through the bonded length. The loaded-end slip has a nonlinear evolution with time during the unloading since the tests were performed under load control in each unloading phase. Note that, in order to guarantee the stability of the test, the unloading was stopped at about $0.5 \mathrm{kN}$ (instead of going down to zero load). It can be observed that the maximum pullout force reached at the end of the reloading, during the cycles, decreases progressively, indicating some degradation of the bond due to the loading applied. In the posterior monotonic loading phase of the tests, both the free-end and loaded-end slips evolve with a similar slope and the pullout force reaches a peak value after which it progressively decreases.

Fig. 7 illustrates the typical evolutions of the slip at the free-end and loaded-end, and of the pullout force for the $\mathrm{C} 1$ series. Until the peak pullout force is reached, there is practically no free-end slip, with some of the loaded-end slip being recovered during the unloading phase. After the peak pullout force, both the free-end and the loaded-end slips increase during the loading phase. In the unloading phase the free-end slip remains constant, whereas the loaded-end slip decreases. This trend can be explained by assuming that the degradation of the interface spreads over the complete bond length at the peak pullout force and any further pullout increases the degradation leading to a decrease in the pullout resistance. Nevertheless, the frictional restraint continues to be significant even after a slip of $5 \mathrm{~mm}$.

Fig. 8 shows the typical relationships between the pullout force and the slip at the free-end and loaded-end $\left(F_{l}-s_{f}\right.$ and $\left.F_{l}-s_{l}\right)$ for the $\mathrm{C} 10$ series. The complete test data of this series can be found in 
Sena-Cruz (2004). The corresponding monotonic curve (Lb120_M) is included in Fig. 8. This curve is the average response of the specimens having the same bond length. The curves of the C10 series are similar in shape to that of the corresponding monotonic test. In the series with bond lengths of $60 \mathrm{~mm}$ and $90 \mathrm{~mm}$ the monotonic curve is an upper bound of the cyclic test results, whereas in the series with a bond length of $120 \mathrm{~mm}$ the monotonic curve is a lower bound (Sena-Cruz 2004).

Fig. 9 illustrates the typical relationship between the loaded-end slip and the pullout force for the cyclic loading phase of the $\mathrm{C} 10$ series. In the first cycle (thick line in Fig. 9), a distinct behavior can be observed: in the unloading branch, the relationship is nonlinear with upward concavity, and in the initial part of the reloading branch the behavior is nonlinear, followed by a linear relationship up to the end of this branch. In subsequent cycles, there is no linear part in the reloading branch.

For the $\mathrm{C} 1$ series, the relationships between the pullout force and the slip at the free-end and loaded-end $\left(F_{l}-s_{f}\right.$ and $\left.F_{l}-s_{l}\right)$ are shown in Fig. 10, along with the corresponding monotonic curve. As expected, the curves of the cyclic tests have a shape that is similar to the monotonic curve. As in the case of the Lb120_C10 series, the monotonic curve is close to the lower bound of the corresponding cyclic test results. Also, the free-end slip remains constant during the unloading and reloading phases, indicating that the bond has not degraded along all its length.

Table 1 presents the values of the parameters derived from the experimental results, as defined in the previous section. In general, the values obtained in cyclic tests are lower than the corresponding results of the monotonic tests with the exception of series Lb120. As seen earlier, the parameters $s_{l \max }, F_{l \max }, \sigma_{l \max } / f_{f u}$ and $\tau_{r} / \tau_{\max }$ tend to increase with the bond length, $L_{b}$, whereas $\tau_{\max }$ decreases with an increase in $L_{b}$.

For the $\mathrm{C} 10$ series, the influence of the number of cycles on the normalized pullout force has been represented in Fig. 11(a). For each test, $F_{l i}$ is the pullout force at the end of the $i$-th reloading branch (see Fig. 2). The influence of the cyclic loading on the strength degradation was similar in all series with an average strength reduction of about $17 \%$. A more significant degradation occurred in the B3_Lb60_C10 specimen, after the fifth cycle, since all the cycles were performed in the post-peak regime. In the remaining specimens, all the cycles were carried out before the peak load was reached. Note that due to inherent variability between the specimens, the cycles did not begin exactly at the desired ratio between $F_{l 0}$ and $F_{l \max }$ (i.e., $60 \%$ for Lb90 series, $75 \%$ for Lb120 series and $90 \%$ for Lb60 series) since the value of $F_{l 0}$ was obtained from the monotonic tests. 
Fig. 11(b) represents the stiffness degradation in the $\mathrm{C} 1$ series. This stiffness has been defined as the slope of the line connecting the points corresponding to the beginning of the unloading and reloading phases. It can be seen that up to the peak pullout force the stiffness decreases significantly, followed by a slight increase in the first part of the softening branch and then a slight decrease. This trend can be attributed to the progressive debonding of the CFRP-adhesive and adhesive-concrete interfaces up to the peak pullout force, along with adhesive cracking. Later, in the post-peak regime, the sudden decay of the pullout force induces the typical increase of stiffness that occurs when materials are submitted to large instantaneous load or displacement variations, as reported by Otter and Naaman (1986). When this phenomenon stabilizes, the bond stiffness is governed by friction between the slipping surfaces and decreases slightly as the slip increases.

\section{Bond Modeling}

\section{Analytical Modeling}

The following differential equation can be taken to govern the slip of the laminate bonded to concrete, as shown by Sena-Cruz and Barros (2004b):

$$
\frac{d^{2} s}{d x^{2}}=\frac{2}{t_{f} E_{f}} \tau
$$

where $t_{f}$ and $E_{f}$ are the thickness and the Young's modulus of the CFRP laminate, respectively, $s$ is the slip, i.e., the relative displacement between the laminate and concrete, $\tau=\tau(s)$ is the local bond stress-slip relationship within the length $d x$, and $\tau$ is the bond stress in the laminate-adhesive interface. Eq. (1) is only valid when the following assumptions hold:

- $\quad$ the CFRP laminate exhibits a linear elastic behavior in the longitudinal direction;

- the deformation of the concrete and adhesive is neglected, along with the slip in the adhesive-concrete interface.

In the present work, the local bond stress-slip relationship is defined by the following functions,

$$
\begin{aligned}
& \tau(s)=\tau_{m}\left(\frac{s}{s_{m}}\right)^{\alpha}, \text { if } s \leq s_{m} \\
& \tau(s)=\tau_{m} \frac{1}{1+\left(\frac{s-s_{m}}{s_{1}}\right)^{\alpha^{\prime}}}, \text { if } s>s_{m}
\end{aligned}
$$


In these equations, $\tau_{m}$ and $s_{m}$ are the bond strength and the corresponding slip, respectively, and $\alpha, \alpha^{\prime}$ and $s_{1}$ are the parameters that define the shape of the corresponding curve. For the current values of $\alpha(0<\alpha<1)$, it can be verified that the initial slope of the line defined by Eq. (2) is equal to infinity, thus leading to a reasonable approximation of the bond stress-slip phenomenon. In fact, the experimental tests carried out in the present work (e.g., see data in Fig. 5) have shown that the slip is negligible for small values of the bond stress.

A numerical strategy was developed (Sena-Cruz and Barros 2004b), using the loaded-end slip and the pullout force values obtained in the pullout-bending tests described in the previous section. This approach yields the values of the parameters $s_{m}, \tau_{m}, \alpha, \alpha^{\prime}$ and $s_{1}$ of Eqs. (2) and (3) by solving Eq. (1). The distribution of the slip and the bond stress along the bond length is taken into account.

Fig. 5(b) shows, for one of the tests in the monotonic series, that the analytically obtained pullout force versus loaded-end slip relationship fits the corresponding experimental results satisfactorily. Similar results have been obtained for the other monotonic series (see Sena-Cruz 2004).

The values of the parameters that define the $\tau(s)$ relationship and the values of the normalized errors obtained in each analysis are presented in Table 2 . The normalized error, $\bar{e}$, is the ratio between $e$ and the area under the experimental curve, where $e$ is the area between the experimental and numerical curves. For each series (composed of three specimens), the experimental curve is the average relationship between the loaded-end slip and the pullout force. Based on the results given in Table 2, the following observations can be made:

- the normalized errors in all the series are acceptable;

- $\quad$ as expected, $s_{m}$ increases with the bond length, since the adhesive deformation is neglected in the present approach;

- a decrease of $\tau_{m}$ with the increase of bond length can be observed. The coefficient of variation of the bond strength is small;

- $\quad$ small coefficients of variation for $s^{\prime}, \alpha$ and $\alpha^{\prime}$ were obtained.

\section{Numerical Modeling}

Several numerical analyses were performed in order to evaluate the influence of the adhesive on the global response of the pullout-bending tests. The horizontal cross-section, at laminate level, of the pullout-bending test was modeled as a plane stress problem. Fig. 12 shows the finite element model used in the simulation of the beams with $120 \mathrm{~mm}$ bond length. In this model, 4-node Lagrangian plane stress elements with $2 \times 2$ Gauss- 
Legendre integration scheme were used to simulate the concrete beam, as well as the adhesive and the CFRP laminate. The bond between the laminate and adhesive was simulated by 4-node line interface elements with two-point Lobatto integration rule. Perfect bond was considered along the adhesive-concrete interface. The concrete and adhesive zones were taken to be $15 \mathrm{~mm}$ thick whereas the thickness of the CFRP laminate and the CFRP-adhesive interface zone was $10 \mathrm{~mm}$. The concrete and the CFRP materials were modeled as linear elastic, considering the moduli of elasticity of $34.4 \mathrm{GPa}$ and $171 \mathrm{GPa}$, and Poisson's ratio of 0.2 and 0.0 , respectively. Assuming that the normal stiffness of the interface element has a marginal effect on the bond behavior, a constant value of $10^{6} \mathrm{~N} / \mathrm{mm}^{3}$ was adopted. According to Schellekens (1992), a value with this order of magnitude is required to avoid numerical instabilities. The values of the parameters used to define the tangential behavior of the interface elements ( $\tau(s)$ relationship) are given in Table 2. A multi-fixed smeared crack model was used to simulate the brittle behavior of the epoxy adhesive (Sena-Cruz 2004). A Young's modulus of 7 GPa, a Poisson's ratio of 0.25 and a tensile strength of 7.0 MPa were adopted for the epoxy adhesive. The load was applied at the loaded-end of the laminate by direct displacement control. All the analyses were performed using the FEMIX computer code, which is a general-purpose finite element program (Azevedo et al. 2003).

The results of the numerical analyses practically coincide with the results obtained analytically. It could be observed that the numerically obtained global response was not affected by the deformation of the adhesive Fig. 12 also shows the crack pattern obtained numerically for the case of the beam Lb120_M. This crack pattern is similar to that observed in the experiments (see Fig. 4).

\section{Conclusions}

The bond performance of the near-surface mounted CFRP laminate strips was assessed by means of pullout-bending tests under monotonic and cyclic loading. The influence of the bond length, $L_{b}$, and the influence of the load history were analyzed by carrying out a series of tests with $L_{b}=60,90$ or $120 \mathrm{~mm}$, under monotonic and cyclic loadings.

Based on the results obtained in the monotonic tests, the following conclusions can be made: the peak pullout force increases with $L_{b}$; the average bond strength ranges from $10 \mathrm{MPa}$ to $14 \mathrm{MPa}$, with a tendency to decrease when $L_{b}$ increases; the maximum tensile stress in the CFRP laminate and the loaded-end slip at peak pullout force increase with $L_{b}$. 
The results of the unloading/reloading tests with a fixed load level lead to the following conclusions: the pullout force versus slip relationships in the cyclic tests and the curve obtained in the corresponding monotonic tests have a similar shape; in the unloading/reloading cycles a decrease of the pullout force at the end of the reloading branches, carried out before the peak pullout force, was observed; and the peak pullout force was not influenced by the cyclic loading.

In the unloading/reloading tests at different slip levels, the stiffness decreases significantly up to the peak pullout force, after which there is a slight increase followed by a smooth decrease.

Using a numerical approach, a local bond stress-slip relationship was obtained from the test results. The parameters that define this relationship were, however, found to be dependent on the bond length. Finite element analysis was performed with the aim of evaluating the influence of the epoxy adhesive on the global response and it was found to be negligible. The crack pattern obtained numerically matches the experimental observations.

\section{Acknowledgements}

The first author wishes to acknowledge the grant SFRH/BD/3259/2000 provided by FCT (Portuguese Foundation for Science and Technology) and FSE (European Social Fund). The tests were performed at the Structural Technology Laboratory of the Technical University of Catalonia, Spain, with the help of Miguel Angel Martín and Ernesto Diaz. The authors wish to acknowledge the support provided by S\&Pß and Bettor MBT $®$ who supplied the material used in the study. 


\section{Notation}

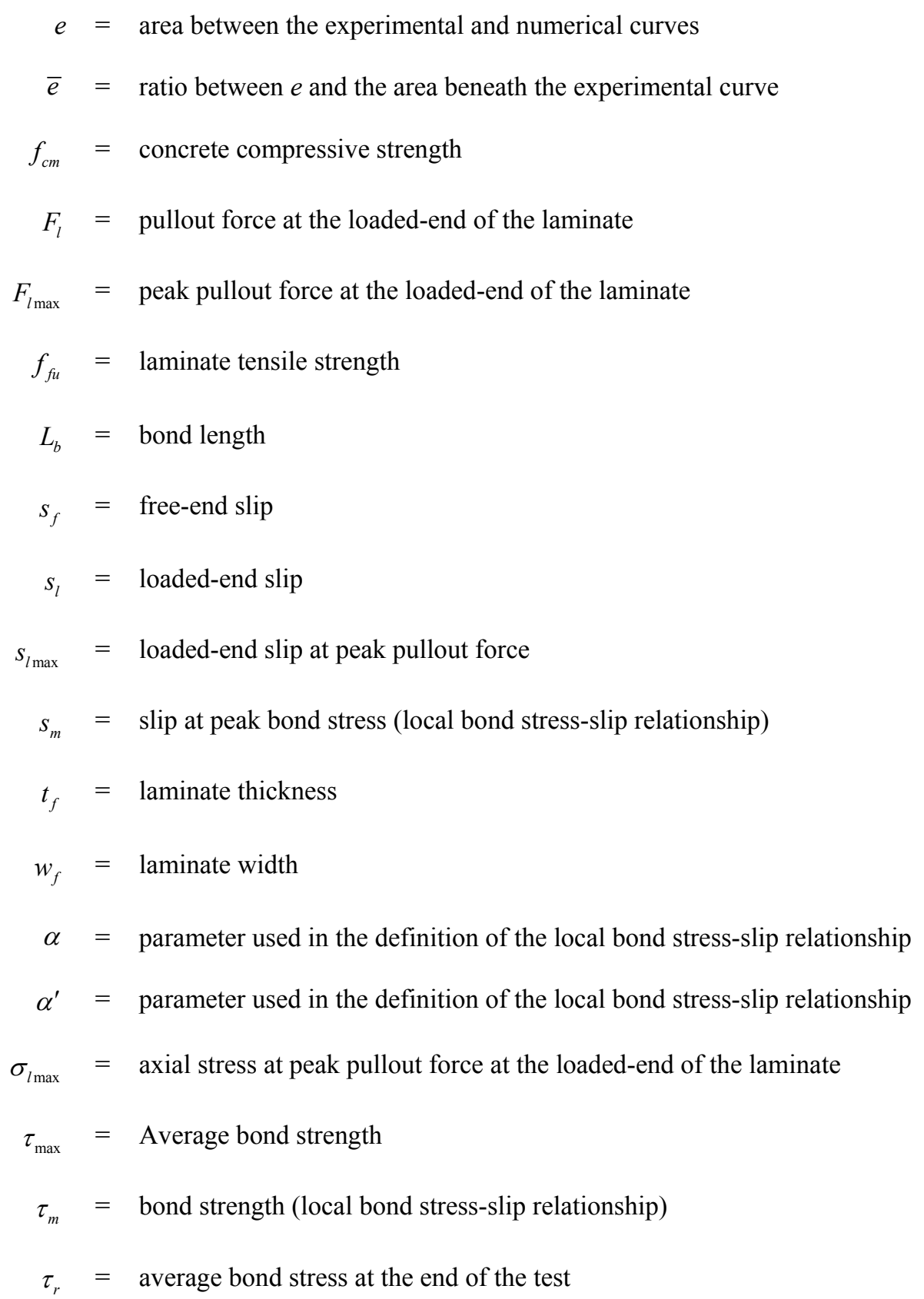




\section{References}

Asplund, S.O. (1949). "Strengthening bridge slabs with grouted reinforcement." ACI J., 20(6), 397-406.

Azevedo, A.F.M., Barros, J.A.O., Sena-Cruz, J.M., and Gouveia, A.V. (2003). "Software no ensino e no projecto de estruturas. Educational software for the design of structures" (in Portuguese). Proc., III Congresso de Luso-Moçambicano de Engenharia, J.S. Gomes, C.F. Afonso, C.C. António and A.S. Matos (eds.), Maputo, Mozambique, 81-92.

Barros, J.A.O., and Fortes, A.S. (2002). "Concrete beams reinforced with carbon laminates bonded into slits." Proc., 5th Congreso de Métodos Numéricos en Ingeniería (CD-Rom), Madrid, Spain, 16 pp., $<$ http://www.civil.uminho.pt/composites $>$ (July 4, 2005).

Barros, J.A.O., and Dias, S.J.E. (2003). "Shear strengthening of reinforced concrete beams with laminate strips of CFRP.” Proc., Int. Conf. of Composites in Construction, D. Bruno, G. Spadea and N. Swamy (eds.), Cosenza, Italy, 289-294, <http://www.civil.uminho.pt/composites> (July 4, 2005).

Cosenza, E., Manfredi, G., and Realfonzo, R. (1997). "Behavior and modeling of bond of FRP rebars to concrete.” J. Compos. Constr., 1(2), 40-51.

De Lorenzis, L., Rizzo, A., and La Tegola, A. (2002). “A modified pull-out test for bond of near-surface mounted FRP rods in concrete.” J. Compos. Part B: Engineering, Elsevier, 33(8), 589-603.

Eligehausen, R., Popov, E.P., and Bertero, V.V. (1983). "Local bond stress-slip relationships of deformed bars under generalized excitations." Rep. No. UCB/EERC-83/23, Earthquake Engineering Research Center, University of California, Berkeley, California, USA.

Ezeldin, A., and Balaguru, P. (1989). "Bond behavior of normal and high strength fiber reinforced concrete." ACI Mater. J., 86, 515-524.

Ferreira, D.R.S.M. (2001). "Pilares de betão armado reforçados com laminados de fibras de carbono. Reinforced concrete columns strengthened with CFRP laminate strips" (in Portuguese). MSc Thesis, Civil Engineering Department, University of Minho, Portugal, <http://www.civil.uminho.pt/composites> (July 4, 2005).

FIB (2000). "Bond of reinforcement in concrete." Bulletin No. 10, The International Federation for Structural Concrete (FIB), State-of-the-art report prepared by Task Group Bond Models (former CEB Task Group 2.5), Lausanne, Switzerland, 427 p. 
Focacci, F., Nanni, A., and Bakis, C.E. (2000). "Local bond-slip relationship for FRP reinforcement in concrete.” J. Compos. Constr., 4(1), 24-31.

Hassan, T. and Rizkalla, S. (2003). "Investigation of bond in concrete structures strengthened with near surface mounted carbon fiber reinforced polymer strips.” J. Compos. Constr., 7(3), 248-257.

ISO 527-5 (1997). "Plastics - Determination of tensile properties - Part 5: Test conditions for unidirectional fibre-reinforced plastic composites.” International Organization for Standardization (ISO), Geneva, Switzerland.

NP-EN 196-1 (1987). “Methods testing cements.” CEN, Brussels, Belgium.

Otter, D., and Naaman, A.E. (1986). "Steel fibre reinforced concrete under static and cyclic compressive loading." RILEM Symposium FRC 86, Developments in Fibre Reinforced Cement and Concrete, 1, Sheffield, UK, paper 3.10.

Schellekens, J.C.J. (1992). “Computational strategies for composite structures.” PhD Thesis, Delft University of Technology, Delft, The Netherlands.

Sena-Cruz, J. M. S., Barros, J. A. O., and Faria, R. M. C. M. (2001). “Assessing the embedded length of epoxy bonded carbon laminates by pull-out bending tests." Proc., Int. Conf. Composites in Construction, Figueiras, J., Juvandes, L., and Faria, R. (eds.), Porto, Portugal, 217-222, $<$ http://www.civil.uminho.pt/composites $>$ (July 4, 2005).

Sena-Cruz, J.M. (2004). "Strengthening of concrete structures with near-surface mounted CFRP laminate strips." PhD Thesis, Department of Civil Engineering, University of Minho, $<$ http://www.civil.uminho.pt/composites $>$ (July 4, 2005).

Sena-Cruz, J.M., and Barros, J.A.O. (2004a). "Bond between near-surface mounted CFRP laminate strips and concrete.” J. Compos. Constr., 8(6), 519-527.

Sena-Cruz, J.M., and Barros, J.A.O. (2004b). "Modeling of bond between near-surface mounted CFRP laminate strips and concrete." Computers \& Structures, Special issue: Computational Mechanics in Portugal, C. Mota Soares and J. Barbosa (eds.), 82/17-19, 1513-1521.

Tan, K., Tumialan, G., and Nanni, A. (2002). "Evaluation of CFRP systems for the strengthening of RC slabs." Rep. No. CIES 02-38, Center for Infrastructure Engineering Studies, University of Missouri-Rolla, Rolla, MO, USA, $121 \mathrm{p}$. 


\section{TABLE CAPTIONS}

Table 1. Average values of the parameters evaluated and coefficients of variation (within parentheses).

Table 2. Values of the parameters defining the local bond stress-slip relationship. 
Table 1. Average values of the parameters evaluated and coefficients of variation (within parentheses).

\begin{tabular}{|l|c|c|c|c|c|}
\hline \multirow{2}{*}{ Series } & $s_{l \max }$ & $F_{l \max }$ & $\tau_{\max }$ & $\sigma_{l \max } / f_{f u}$ & $\tau_{r} / \tau_{\max }$ \\
& {$[\mathrm{mm}]$} & {$[\mathrm{kN}]$} & {$[\mathrm{MPa}]$} & {$[\%]$} & 47.5 \\
\hline Lb60_M & $0.43( \pm 11.3 \%)$ & $18.7( \pm 5.1 \%)$ & 15.6 & $0.45( \pm 4.9 \%)$ \\
\hline Lb90_M & $0.79( \pm 9.0 \%)$ & $23.9( \pm 4.1 \%)$ & 13.3 & 60.7 & $0.52( \pm 2.2 \%)$ \\
\hline Lb120_M & $1.13( \pm 8.1 \%)$ & $27.7( \pm 2.8 \%)$ & 11.5 & 70.5 & $0.54( \pm 0.9 \%)$ \\
\hline Lb60_C10 & $0.35( \pm 13.4 \%)$ & $16.6( \pm 5.2 \%)$ & 13.8 & 42.2 & $0.43( \pm 3.6 \%)$ \\
\hline Lb90_C10 & $0.69( \pm 12.0 \%)$ & $22.2( \pm 4.7 \%)$ & 12.3 & 56.4 & $0.49( \pm 3.1 \%)$ \\
\hline Lb120_C10 & $1.20( \pm 8.4 \%)$ & $28.8( \pm 4.1 \%)$ & 12.0 & 73.2 & $0.56( \pm 2.6 \%)$ \\
\hline Lb120_C1 & $1.18(2.8 \%)$ & $29.6( \pm 6.9 \%)$ & 12.3 & 75.5 & $0.54( \pm 1.4 \%)$ \\
\hline \hline
\end{tabular}


Table 2. Values of the parameters defining the local bond stress-slip relationship.

\begin{tabular}{|c|c|c|c|c|c|c|}
\hline \hline Series & $s_{m}[\mathrm{~mm}]$ & $s_{1}[\mathrm{~mm}]$ & $\tau_{m}[\mathrm{MPa}]$ & $\alpha$ & $\alpha^{\prime}$ & $\bar{e}[\%]$ \\
\hline Lb60_M & 0.26 & 1.8 & 17.5 & 0.40 & 0.40 & 1.2 \\
\hline Lb90_M & 0.45 & 2.0 & 15.7 & 0.45 & 0.35 & 1.6 \\
\hline Lb120_M & 0.47 & 2.0 & 14.3 & 0.50 & 0.41 & 2.5 \\
\hline Average & 0.39 & 1.9 & 15.8 & 0.45 & 0.39 & - \\
$( \pm 29.5 \%)$ & $( \pm 6.0 \%)$ & $( \pm 10.1 \%)$ & $( \pm 11.1 \%)$ & $( \pm 8.3 \%)$ & \\
\hline \hline
\end{tabular}

Note: the values in parentheses are the coefficients of variation of the corresponding series. 


\section{FIGURE CAPTIONS}

Fig. 1. Specimen geometry and test configuration (All dimensions are in $\mathrm{mm}$ ).

Fig. 2. Loading scheme of the $\mathrm{C} 10$ cyclic tests.

Fig. 3. Loading scheme of the $\mathrm{C} 1$ cyclic tests.

Fig. 4. Photo of the crack pattern observed in the laminate-adhesive-concrete bonding zone.

Fig. 5. Variation of pullout force with (a) free-end slip and (b) loaded-end slip for the Lb120_M series.

Fig. 6. Evolution of the slip at the free-end and loaded-end, and of the pullout force of the first specimen of series Lb120_C10.

Fig. 7. Evolution of the slip at the free-end and loaded-end, and of the pullout force of the first specimen of series Lb120_C1.

Fig. 8. Variation of the pullout force with (a) free-end slip and (b) loaded-end slip (b) for the Lb120_C10 series.

Fig. 9. Curves of the pullout force vs. loaded-end slip of B1_Lb60_C10 specimen during all the cycles.

Fig. 10. Variation of the pullout force with (a) free-end slip and (b) loaded-end slip for the Lb120_C1 series.

Fig. 11. (a) Normalized pullout force as a function of the number of cycles; (b) stiffness degradation in the Lb120_C1 series.

Fig. 12. Finite model: geometry, mesh, loading configuration, support conditions and crack pattern (All dimensions are in $\mathrm{mm}$ ). 


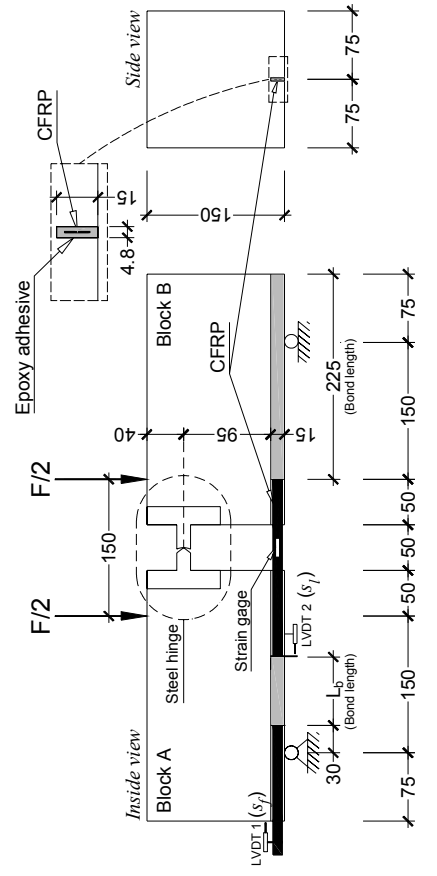

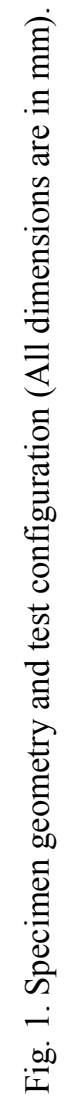



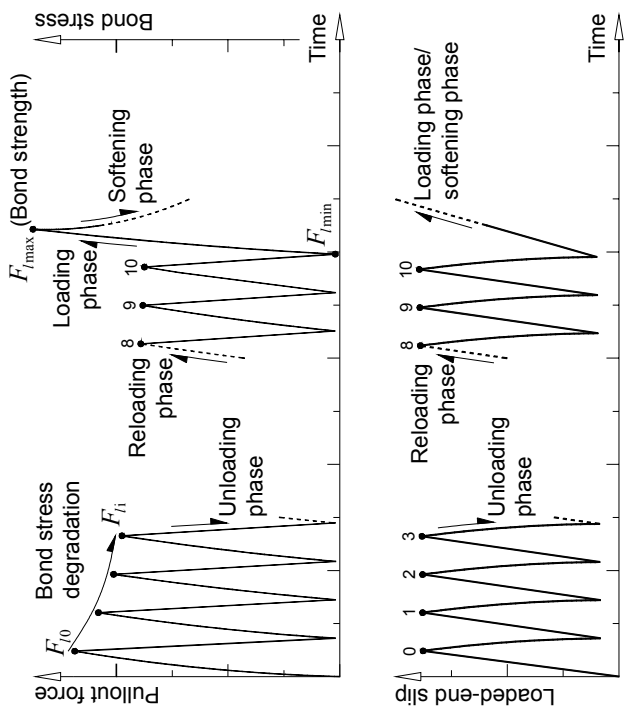

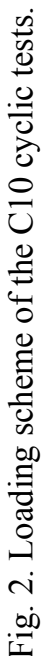




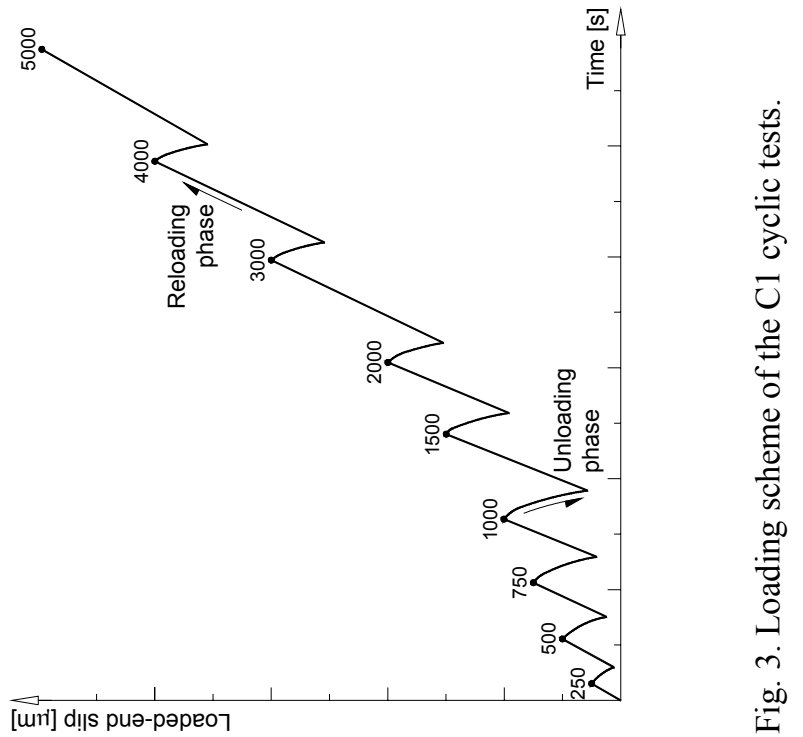




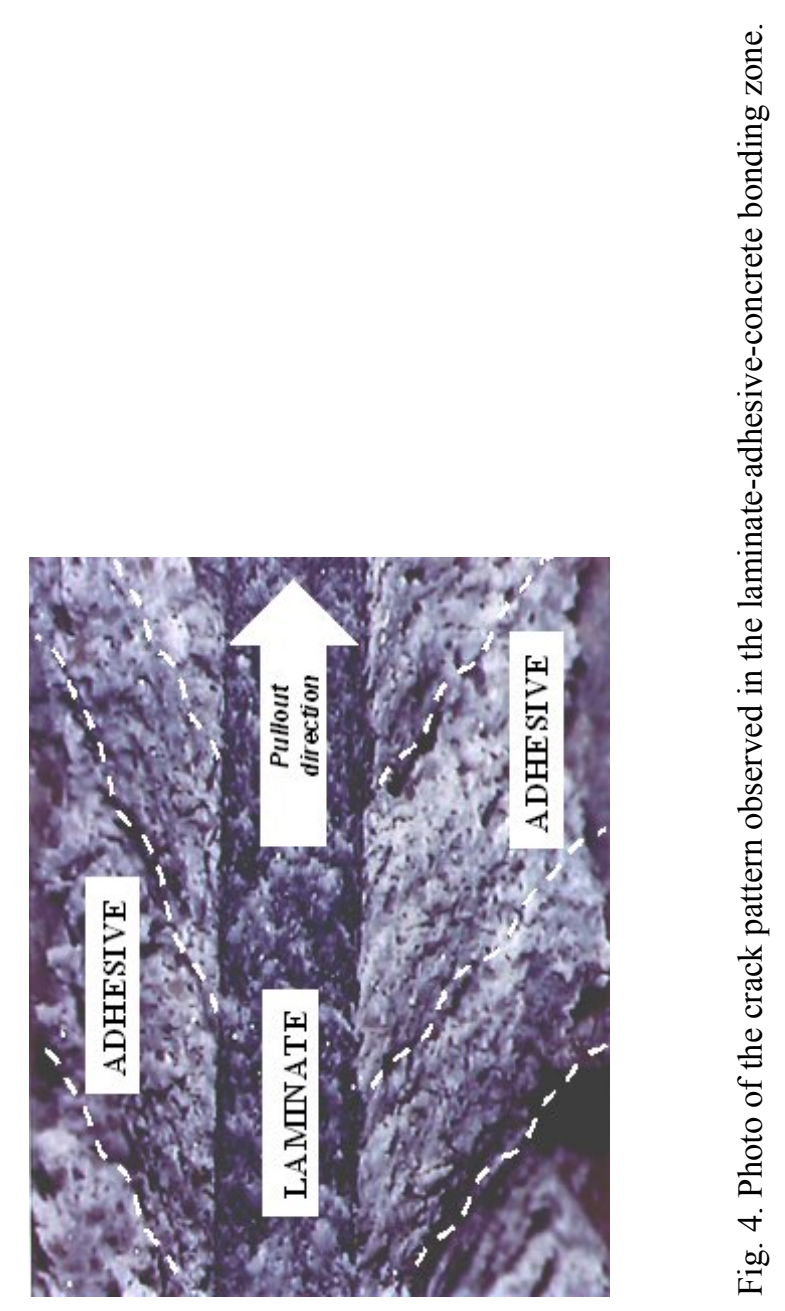




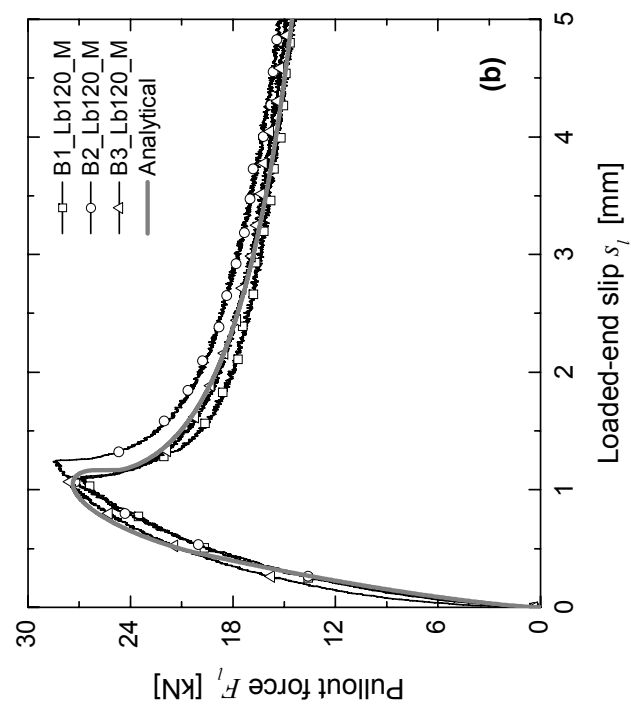

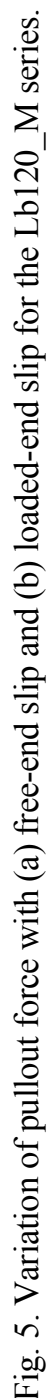

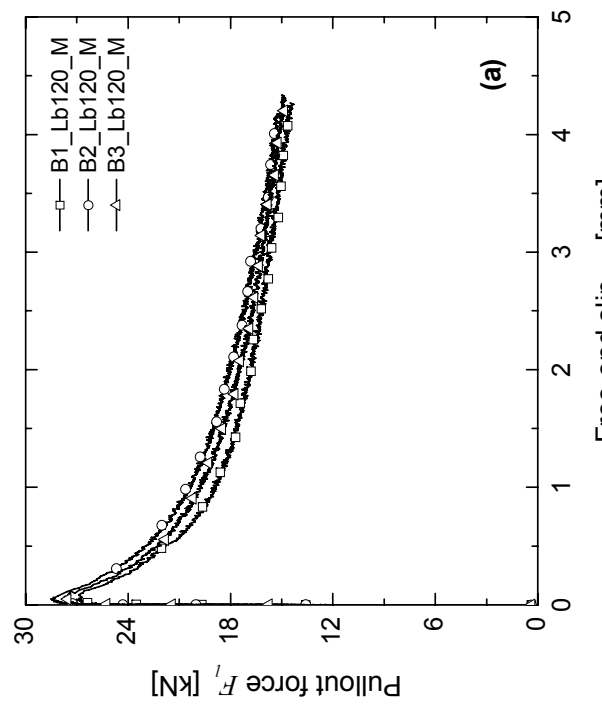

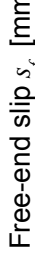




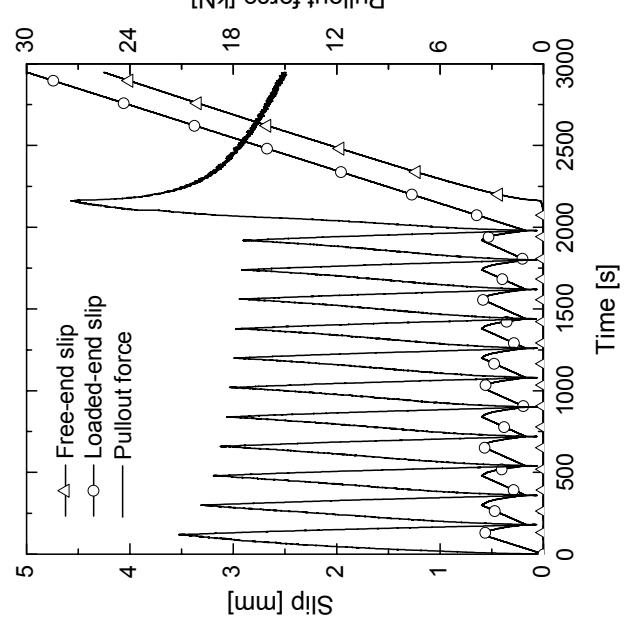




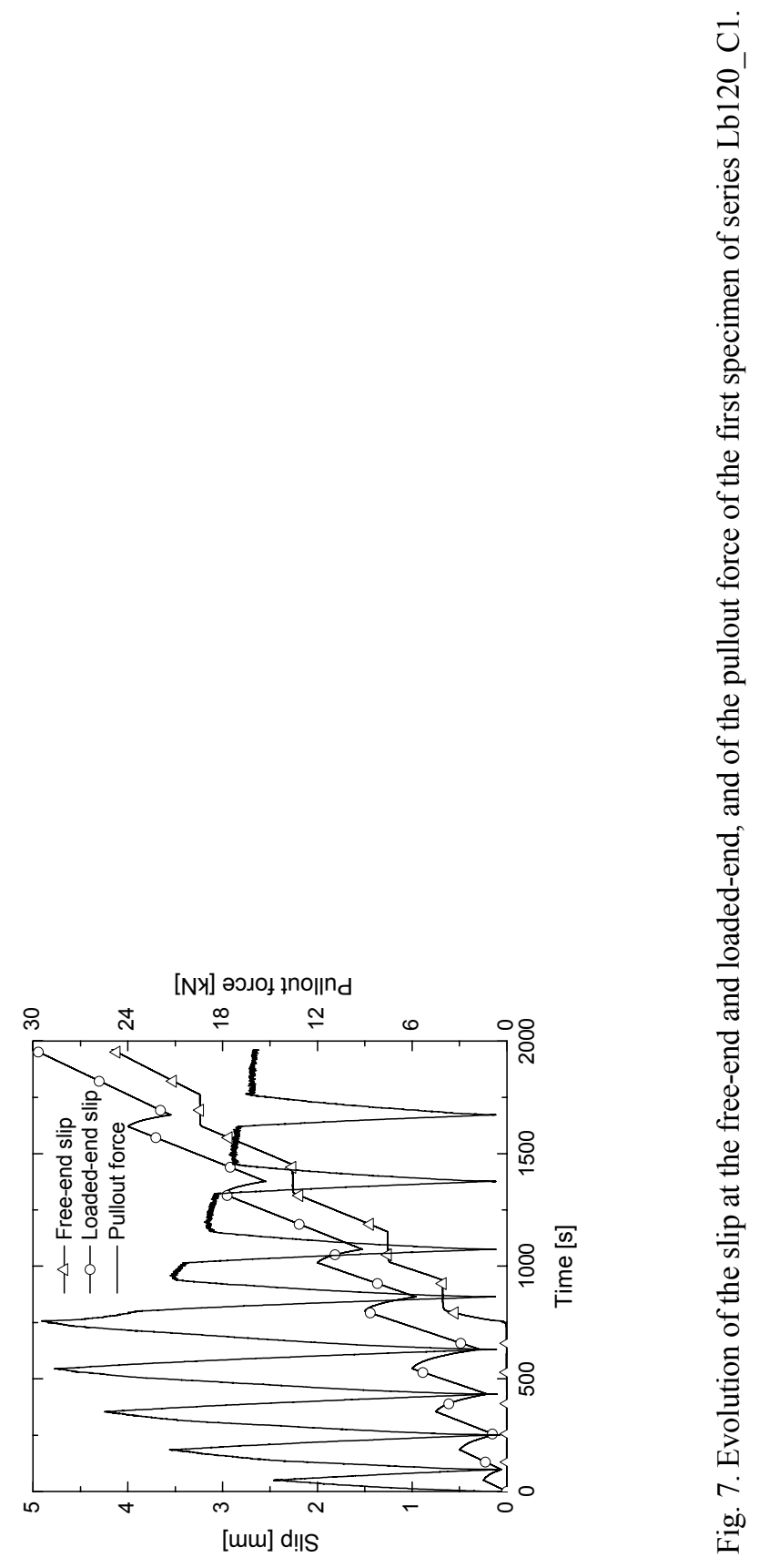




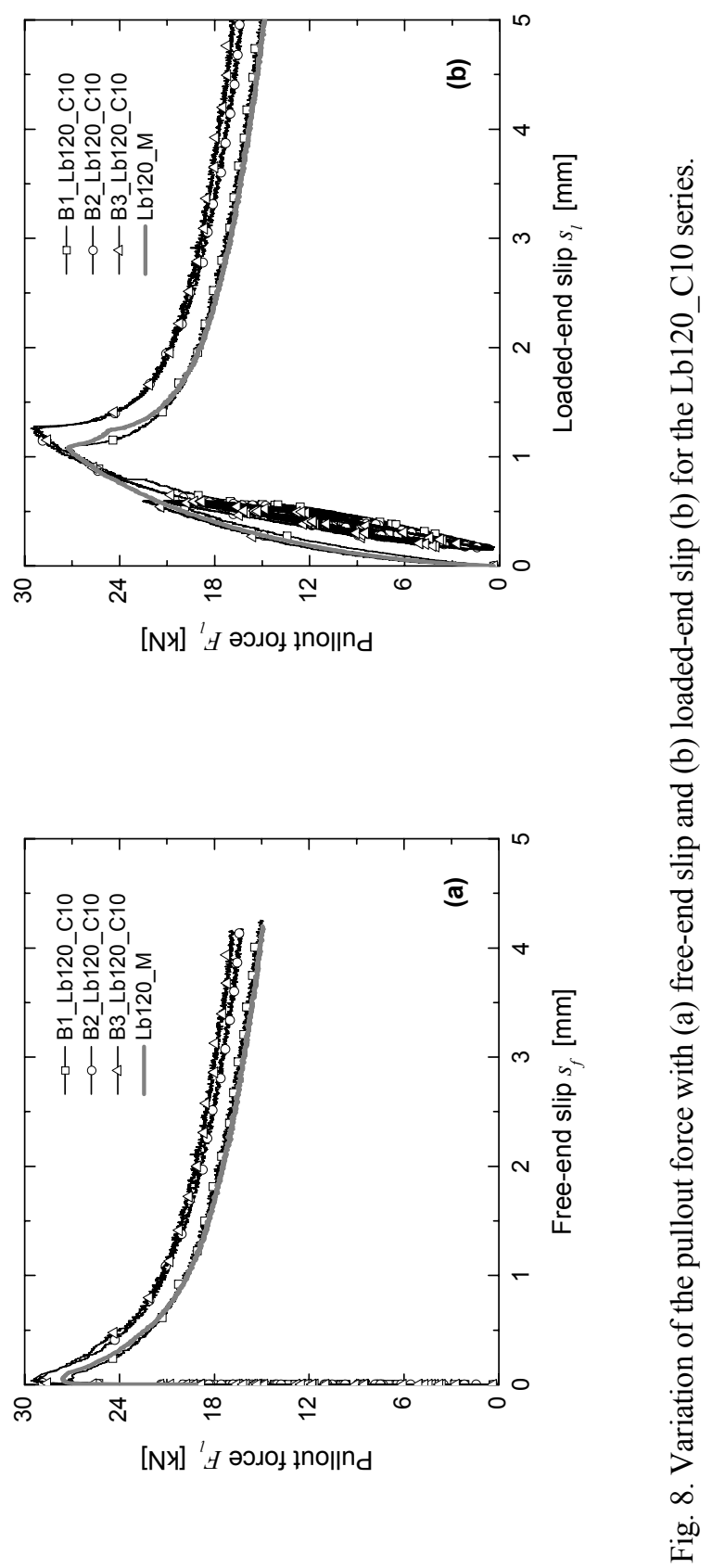




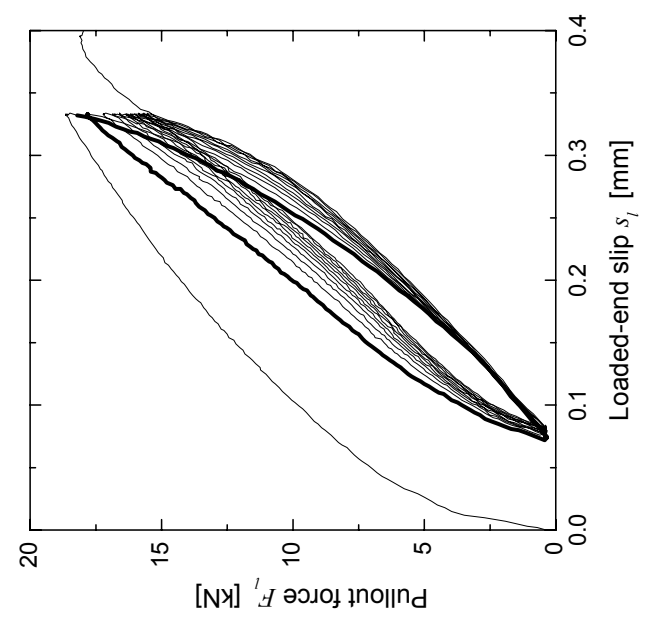

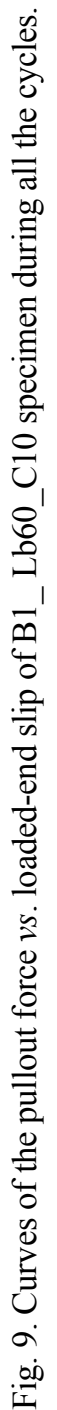




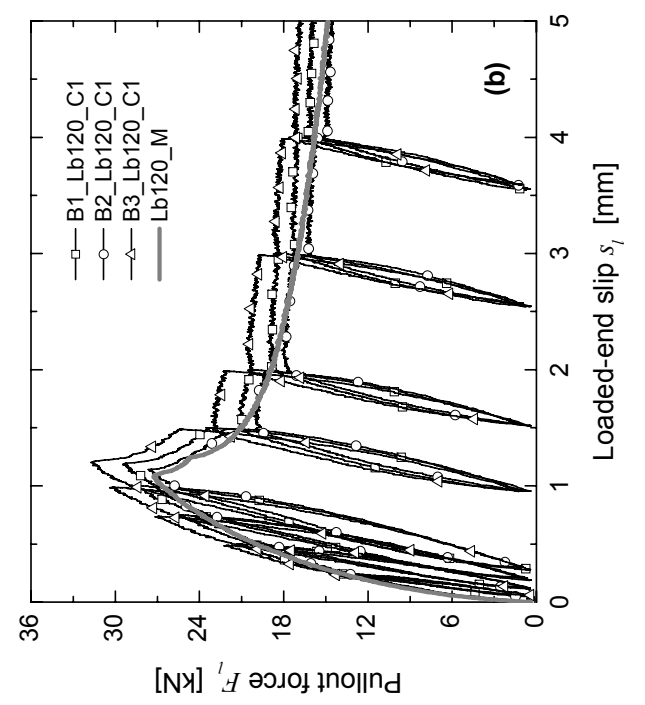

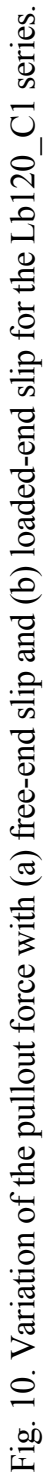

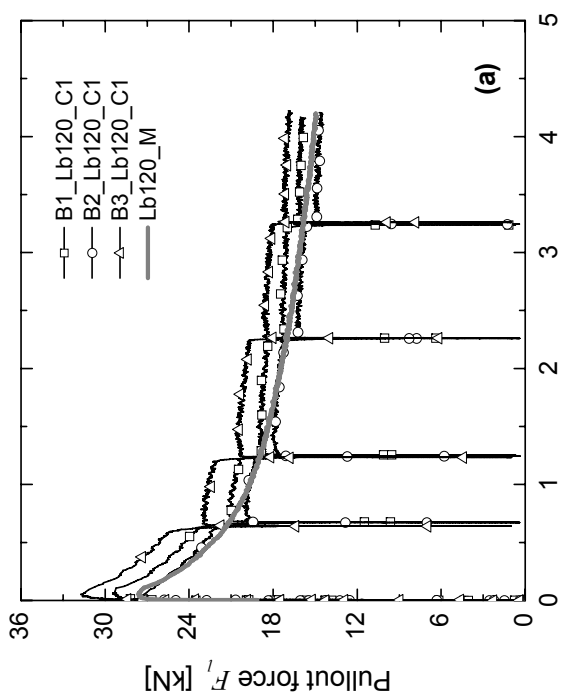




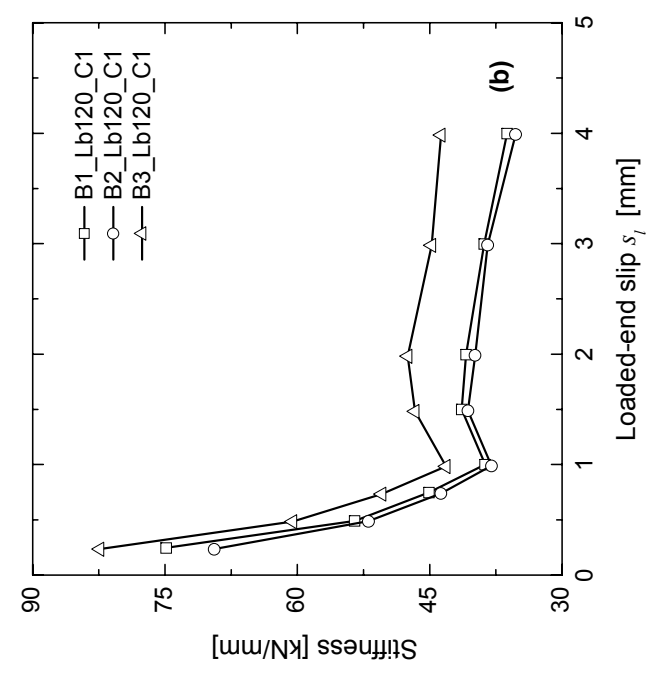

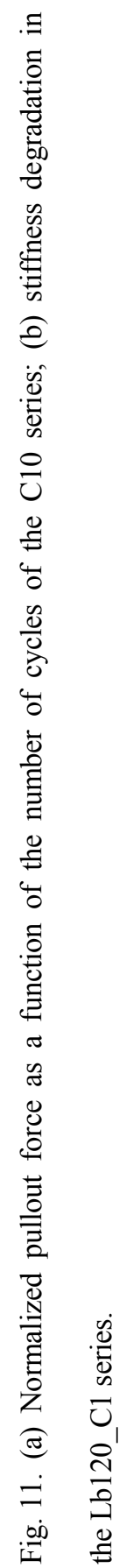

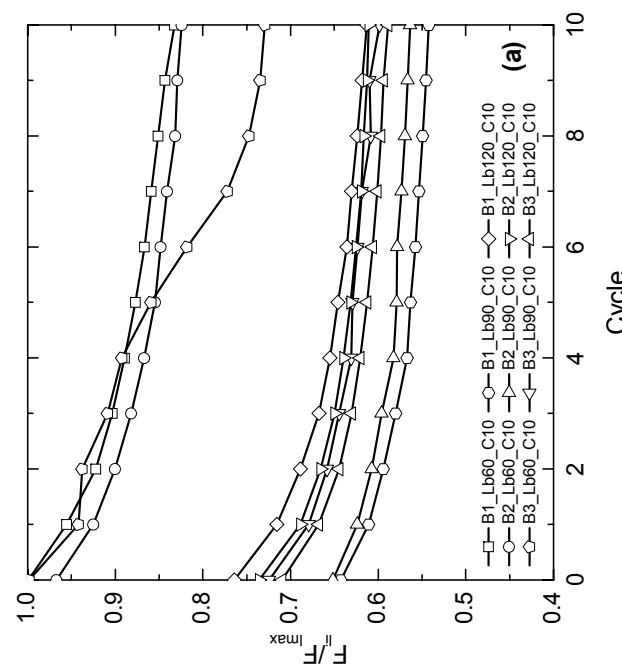




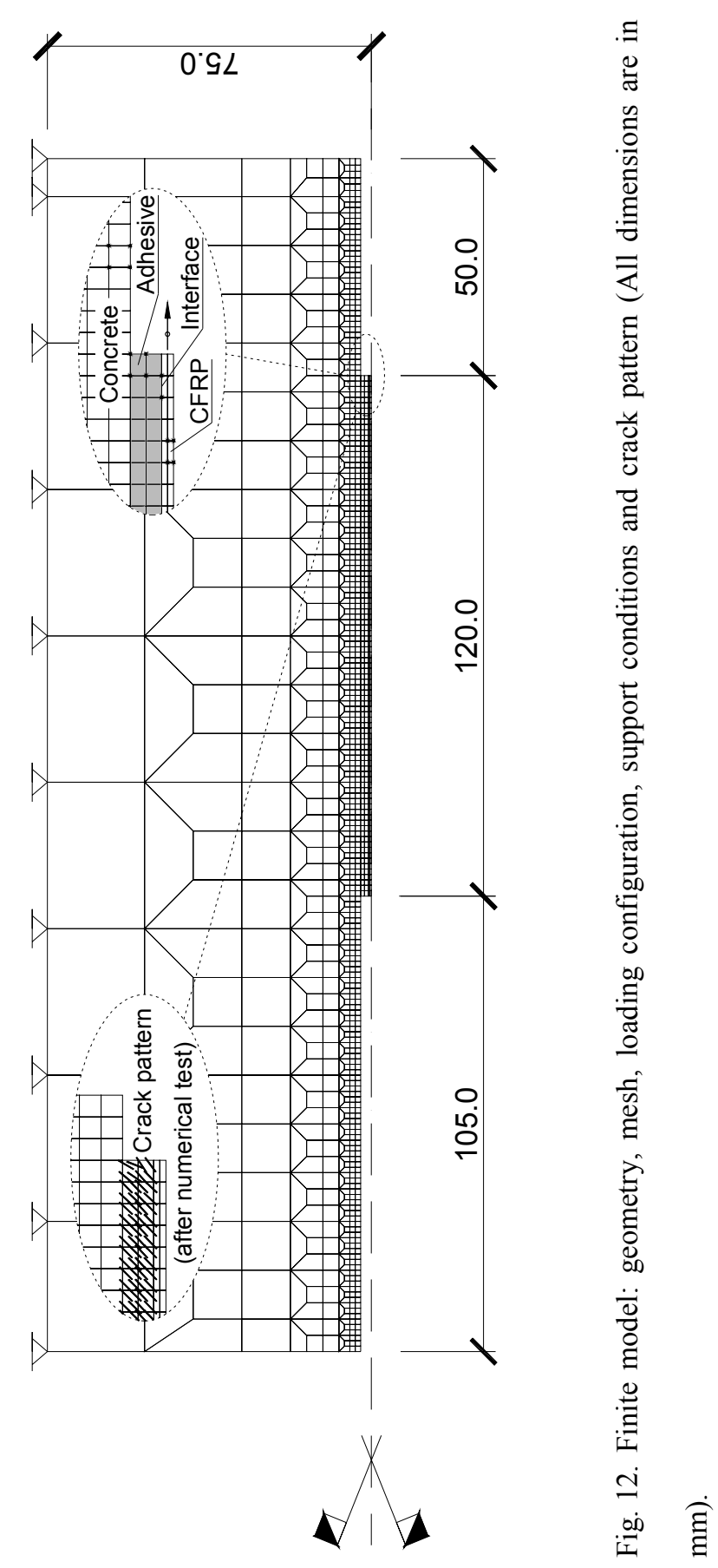

